\title{
Estimating the income inequality-health rela- tionship for the United States between 1941 and 2015: Will the relevant frequencies please stand up?
}

\section{Jürgen Antony ${ }^{1}$ and Torben Klarl ${ }^{2,3}$}

June 2020

\begin{abstract}
The income inequality hypothesis $(\mathrm{IIH})$ predicts that income inequality itself is the major determinant of population health. A novel continuous wavelet approach allows us to directly estimate the association between health and income inequality for the U.S. between 1941 and 2015 simultaneously, at any frequency and time domain. After controlling for gender, aggregate income, governmental spendings on health and education, the paper finds, first, that the frequency domain is relevant for identifying any relationship between health and income inequality, but, second, the overall evidence for the IIH is weak. Only for the time span 1956-1993 and for long-run frequencies, we find that an increase of income inequality has adverse effects on health. We are not able to confirm the existence of the IIH for any other time periods at different frequencies, even not for the period of the recent financial crisis. Hence, the empirical confirmation of the $\mathrm{IIH}$ is the rare exemption rather than the rule and its existence, at least on an aggregate level, clearly depends on the frequency domain.
\end{abstract}

\section{Keywords}

Health, Inequality, Wavelets, Time and frequency estimation

\section{JEL Classifications}

I14, I1, I12, E25

\footnotetext{
${ }^{1}$ Pforzheim Business School, Pforzheim University, Tiefenbronner Straße 65, 75175 Pforzheim

${ }^{2}$ Corresponding author. University of Bremen, Faculty of Business Studies and Economics,

Max-von-Laue-Straße 1, 28359 Bremen

${ }^{3}$ Research Fellow at SPEA, Indiana University, Bloomington,

1315 E. Tenth Street, Bloomington, IN 47405-1701, United States

e-mail: jurgen.antony@hs-pforzheim.de, tklarl@uni-bremen.de.
} 


\section{Motivation}

Using U.S. data for the years 1941-2015, this paper asks the question whether an egalitarian society is beneficial for its members' health status. Since Wilkinson's (1992) study, a large number of crosscountry or longitudinal studies find that income inequality has deleterious effects on health (among others, see Lynch and Kaplan (1997) or Kawachi et al. (1997a, 1997b)) while others do not (e.g. Mellor and Milyo (2001) or Deaton (2003)). Although, the evidence for this so called income inequality hypothesis is mixed (see Truesdale and Jencks (2016)), it nevertheless greatly influenced the public media, policy makers as well as grant-making institutions making them believe that income inequality causes poor health ${ }^{1}$.

The great communality of many studies is that they either exploit the time dimension, the crosssectional dimension or both dimensions simultaneously. Astonishingly, these studies paid no attention to the nature of shocks per se that might affect the $\mathrm{IHH}$ at different frequencies over time. For instance, if shocks affecting the $\mathrm{IH}$ today are more short-lived compared to the past, ignoring this change of the frequency domain in the data might lead to a rejection of the $\mathrm{IIH}$ at the time domain. Further, it might also be possible that shocks cancel out if we aggregate over all frequencies, which again, leads to a rejection of the $\mathrm{IHH}$ even if it exists at some frequencies. In other words, ex ante, there is no reason to assume that the World War II influenced the health status-income inequality relationship exactly in the same way as the recent sub-prime crises ${ }^{2}$. In this paper we argue that ignoring the frequency domain is obviously a gross oversimplification when it comes to an investigation of the association between income inequality and health status over a long period of time.

Contribution to the literature. This paper is the first exploiting both the time and frequency dimension of the $\mathrm{IIH}$. Overall, our findings show that there is no strong empirical support for the contention that income inequality is detrimental to a society's health. After controlling for gender, aggregate income, governmental spendings on health and education, the paper finds, first, that the frequency domain is relevant for identifying any relationship between health and income inequality, but, second, the overall evidence for the IIH is weak. Only for the time span 1956-1993 and for long-run frequencies, we find that an increase of income inequality has adverse effects on health. Hence, rising income allows people to purchase higher-quality goods that are beneficial to their health. Further, using wavelets, we can directly check the existence of a possible reverse relationship between health and income inequality: If people with a good health status are more able to work and therefore benefit from immediate higher earnings (e.g. Cutler et al. (2011) or Garcia Gomez et al. (2013)), this might reduce inequality, given that the relationship between income and health is

\footnotetext{
${ }^{1}$ The literature distinguishes the relative or weak from the absolute or strong $\mathrm{IH}$. The relative or weak $\mathrm{IH}$ assumes that what matters for health is the individual's income relative to her reference group. Instead, the strong IIH states that inequality itself matters, independently of an individual's own income.

${ }^{2}$ Standard, linear time-series domain regression approaches implicitly assume that a possible linear relationship holds across all frequencies.
} 
concave ${ }^{3}$.

Our study offers several new innovations over the existing literature which are grounded on a reinvestigation of the $\mathrm{IH}$ from a macroeconomic perspective due to three important reasons: First, the long-term impact of income inequality on health has not been fully explored in the current literature (see Zheng (2012)). As pointed out by Mellor and Milyo (2001), the validity of results regarding the IIH obtained so far also suffer from the fact that this relationship is only investigated over a short period of time. Second, and in contrast to our study, the short-or long-term link between income inequality and health on an aggregate level was often investigated without controlling for other covariates. Third, and to the best of our knowledge, none of the relevant contributions have simultaneously investigated this relationship in the time and frequency domain.

However, there are good reasons to incorporate the frequency dimension in our analysis of the $\mathrm{IIH}$ : If we investigate the link between income inequality and health over time, this relationship might be hit by several shocks which normally differ in their size and persistence. Hence, for the same discrete time span we might observe different causal lead-lag patterns of the income inequality-health relationship. As we are going to investigate this relationship between 1941 and 2015, the assumptions that shocks during that time are homogenous and/or do not differ over frequencies in their impact on the income inequality-health relationship is clearly a drawback coming along with the application of pure time-series techniques. Leaving out the frequency domain might be a further explanation why the empirical literature is rather inconclusive regarding the existence of a relationship predicted by the (strong/weak) IIH. Moreover, considering the frequency domain is also a valuable source for an appropriate design of health policies. For instance, if only short-lived shocks are relevant affecting the income inequality-health relationship, a policy design might be biased if it aims to mitigate the consequences of long-run instead of short-run shocks. To sum up, our suggested methodology allows both, to investigate the effects of short term fluctuations in income (see Ruhm $(2000,2005)$ ) and changes in permanent income on the health status (Deaton and Paxson (2004)).

It is rather obvious that the $\mathrm{IH}$ does not necessarily imply a causal relationship. For instance, in order to account for confounding and previously omitted factors in the income inequality-health relationship, we, first, include additional controls for U.S. government spendings on education as well as GDP per capita. Hence, in this way we control for the possibility that the primary pathways through which income inequality affects health is education as suggested by Grossman (1972, 1975, 2000) or aggregate income instead of income inequality per $\mathrm{se}^{4}$. Moreover, as predicted by the MeltzerRichard theorem (1981), more inequality may be associated with higher government spendings on health care. That is why we also add governmental health spendings as a further control variable. Further, due to the fact that changes in inequality might affect health, we use first differences of variables instead of their levels. Finally, we also control for gender. It turns out that controlling

\footnotetext{
${ }^{3}$ If this is the case, income has a smaller effect on health and longevity among the rich than among the poor.

${ }^{4}$ For instance, highly educated agents might be better informed of treatment options (among others, see Bago d'Uva et al. (2008) or Glied and Lleras-Muney (2008)), which might lead to a comparably better health status on average.
} 
Estimating the income inequality-health relationship for the United States between 1941 and 2015: Will the relevant frequencies please stand up?

for these issues, most of the income inequality-health relationship is quashed over the time and frequency domain.

This paper adopts the continuous wavelet tools to investigate the dynamic relationship between health status and income inequality. Reflecting the relevant literature, the number of contributions employing this approach is steadily increasing. For instance, it has been used to discuss cycles in politics (Aguiar-Conraria and Soares $(2012,2013)$ ), the estimation of the Taylor rule (Aguiar-Conraria et al. (2018a)), the analysis of (regional) house price cycles and the role of monetary policy (Klarl (2016) and Flor and Klarl (2017)) or the investigation of California's carbon market and energy prices (Aguiar-Conraria et al. (2018b)). We further use the recently introduced concept of the so-called partial wavelet gain (see Aguiar-Conraria et al. (2018a, 2018b), Verona (2019)) in order to quantify the magnitude of the impact of income inequality on health. In particular, the latter concept allows to estimate regression coefficients in the time-frequency domain ${ }^{5}$. Section 3 of this paper provides a controlled experimental study to show the reader the intuition behind these tools.

The paper finds the following: First, for all considered frequencies over the period 1941-2015, and after controlling for aggregate income, gender, governmental spendings on health and education, there is only one period (1956-1993) where we can confirm the existence of the $\mathrm{IIH}$ at longer-run frequencies (15-20 years). This relationship is more pronounced for men than for women ${ }^{6}$. We are not able to confirm the existence of the $\mathrm{IIH}$ for any other time periods at different frequencies, even not for the period of the recent financial crisis. Moreover, the results are robust to an additional measure for inequality, the top $1 \%$ in gross income. In summary, the empirical confirmation of the $\mathrm{IIH}$ is the rare exemption rather than the rule and its existence, at least on an aggregate level, depends on the frequency domain. Hence, it is definitely not "[...] clear that the scale of income differences in a society is one of the most powerful determinants of health" (Wilkinson (1996), ix).

The plan of the paper is as follows. Section 2 provides a short review of the relevant literature. Section 3 briefly motivates the continuous wavelet methodology with the help of a controlled experiment. Section 4 presents the data. Section 5 shows the results, whereas section 6 discusses the main findings. Section 7 concludes.

\section{Related Literature}

The investigation of the link between health and income produced an enormous volume of literature. A large strand of literature focused on the (mental/physical) health-income relationship in a growth context (see Ruhm (2000, 2003, 2005), van den Berg et al. (2017), Swift (2011), Chen (2017),

\footnotetext{
${ }^{5}$ From a methodological point of view, exactly this point makes our paper different from, inter alia, Svensson and Krüger (2012) or Chen (2017).

${ }^{6}$ One explanation for this finding is that during 1956-1993, shocks such as the Vietnam and the second Gulf war have a stronger effect for men's than for women's life expectancy. Also in that time span, the HI-virus, which jumped from the Caribbean to the U.S. around 1980 triggered the country's AIDS epidemic that affects men relatively more than women (see https://www.hiv.gov/hiv-basics/overview/data-and-trends/statistics).
} 
Estimating the income inequality-health relationship for the United States between 1941 and 2015: Will the relevant frequencies please stand up?

Gerdtham and Johannesson (2005), Lam and Piérard (2017) or Svensson and Krüger (2012)). See Hollingsworth et al. (2018) for a recent review of much of this research.

A second strand of literature has investigated the health effects of income inequality. The link between income inequality and health has been repeatedly observed across countries (see Rogers (1979), Flegg (1982), Wilkinson $(1992,1996))$, and across smaller geographical entities, such as states and metropolitan areas in the U.S. (Kaplan et al. (1996), Kawachi et al. (1997a and 1997b), Lynch et al. (1998)). For the U.S., it has been further asserted that this relationship is rather robust irrespective of the exact measure of health status and income inequality (see Lynch et al. (1998)). Reflecting over 100 studies, Clarkwest and Jencks (2003) conclude that among scholars there is consensus that there is definitely a connection between health and income inequality.

Apart from that, Mellor and Milyo (2001) point out that the association between health and income inequality on an aggregate level is sensitive to the specific time period (see also Judge (1995), Judge et al. (1998)) and the inclusion of relevant control variables. For the period 2001-2014, Chetty et al. (2016) found that higher income was associated with greater longevity, and that differences in life expectancy across income groups increased over time. Further, the authors pointed to the fact that local areas characteristics and health behaviors are significant driving forces explaining the $\mathrm{IIH}$ (see also Francovic and Kuhn (2019)). Deaton (2003) and Leigh et al. (2009) emphasize a possible reverse causation, which if it is not adequately addressed, in turn fails to establish a causal link running from income inequality to health.

Although not the focus of this paper, some studies have tackled the validity of the $\mathrm{IIH}$ also on the individual level (among others see Mellor and Milyo (2001, 2002); see also Deaton (2003) for a superb overview.). Compared to aggregate studies, these strand of literature show a weaker or even no relationship between income inequality and health.

However, many studies are limited by small sample sizes, inadequate data, and selection and heterogeneity biases (see Mellor and Milyo (2001), Beckfield (2004) or Babones (2008) for a discussion). In particular, from an aggregate perspective, local area or individual characteristics might cancel out, leading to an erroneously rejection of the $\mathrm{IHH}$. Although more recent work takes steps to ameliorate some of these issues, results are still not conclusive, partly due to the use of different methodologies and control variables. A direct comparison of studies is therefore not a straightforward exercise (Torre and Myrskylä (2014)).

To sum up, there is less consensus in the literature whether or not there is evidence for the $\mathrm{IHH}$ to be true, not only for the U.S.: "[...] There seems to be little support for the idea that income inequality is a major, generalizable determinant of population health differences within or between rich countries" (Lynch (2004), p.5.). We add to this literature by showing that besides the time dimension and the inclusion of further controls, the link between health and income is also sensitive towards the frequency dimension. In contrast to the before mentioned studies, we take the heterogeneity of shocks and their potential asymmetric influence they might have on the association between income inequality and health status into account. 


\section{A valuable tool for empirical economics: Continuous Wavelets within a controlled experiment}

This section first provides an intuitive example following Aguiar-Conraria et al. (2018a). For an intuitive explanation of the continuous wavelets methodology, the interested reader is also referred to Aguiar-Conraria et al. $(2012,2013)^{7}$. Unlike to standard linear time series approaches, the wavelet approach does not impose the implicit assumption that a linear relationship between variables is identical across all frequencies. When it comes to an analysis of dynamic relationships in economics, the natural way to exploit the information contained in this relationship is to use well established dynamic panel or time-series tools. However, like others, we argue that neglecting the frequency domain and, hence, solely focusing on the time domain may lead to biased conclusions regarding a potential dynamic relationship between two or several variables. We will use the following controlled experiment to make this striking point clear.

Consider that we have three time-series, $X_{t}, Y_{t}$ and $Z_{t}$, for $t=\{1, \ldots, 200\}$ which are measured on a quarterly base ${ }^{8}$. For instance, a researcher uses life expectancy at birth data $\left(Y_{t}\right)$ to find out whether or not life expectancy at birth is related to the business cycle $\left(X_{t}\right)^{9}$. To obtain the cycle component of a time-series, one prominent way is to use the Hodrick-Prescott (HP) filter. However, this filter may be too restrictive: By reconsidering the relationship between life expectancy at birth and the business cycle, van den Berg et al. (2017) on page 67 pointed out that the "trend estimates clearly contain cyclical variation hence absorbing information of the business cycle that we wish to capture by the cyclical component". We exactly address this problem by suggesting wavelets.

For our experiment, we generate the variables in the following way ${ }^{10}$ :

$$
\begin{aligned}
& X_{t}=\sin \left(2 \pi \frac{t}{2}\right)+\sin \left(2 \pi \frac{t}{5}\right)+\epsilon_{X, t}, \\
& Z_{t}=\cos \left(2 \pi \frac{t}{6}\right)+\epsilon_{Z, t}, \\
& Y_{t}=\left\{\begin{array}{l}
1.15 \sin \left(2 \pi \frac{t+0.25}{2}\right)+\sin \left(2 \pi \frac{t-1}{5}\right)+\epsilon_{Y, t} \text { for } t \leq 100 \\
1.15 \sin \left(2 \pi \frac{t+0.25}{2}\right)-2 \sin \left(2 \pi \frac{t-1}{5}\right)+\epsilon_{Y, t} \text { for } t>100
\end{array}\right.
\end{aligned}
$$

where the errors $\epsilon_{i, t}, i \in\{X, Z, Y\}$ are i.i.d. We note that there is a structural break in the time series realization for $Y_{t}$ at $t=100$ which might be caused by a severe financial crisis or a medical innovation. The first shock might affect the IIH at higher frequencies (at the business cycle), whereas the latter shock might affect the $\mathrm{IH}$ at longer frequencies. Again, it is impossible to distinguish the

\footnotetext{
${ }^{7}$ The results in this paper were obtained using the Matlab toolbox ASToolbox2018, which is available at https://sites.google.com/site/aguiarconraria/joanasoares-wavelets/the-astool-box and cross-checked by our own Matlab programs and the R-package WaveletComp. We are grateful to Luis Aguiar-Conraria and Maria Joana Soares for sharing their toolbox.

${ }^{8}$ We have to clearly point out that the choice of the frequency does not change the overall findings.

${ }^{9}$ See Ruhm $(2000,2005)$ for instance.

${ }^{10}$ Figure (1) in Appendix A.1 shows the time series.
} 
Estimating the income inequality-health relationship for the United States between 1941 and 2015: Will the relevant frequencies please stand up?

nature of these shocks as well as their potential different influence on the IIH by running standard time series regression ignoring the frequency domain. Related to our example, what do we expect from this experiment when we regress $Y_{t}$ (say health status) on $X_{t}$ (say income inequality) as well as on $Z_{t}$ (which could be education)? In general, we observe that variable $Z_{t}$ directly influences $Y_{t}$ and $X_{t}$. Thus, regressing $Y_{t}$ on $X_{t}$ by not controlling for the influence of $Z_{t}$ would lead to a biased estimate as income might effect both, income inequality as well as health status. For a moment, let us ignore the influence of $Z_{t}$. By regressing $Y_{t}$ on $X_{t}$ using OLS, at frequencies that correspond to a period of 2 years, we would obtain an estimated coefficient of around 1.15. At frequencies that correspond to a period of 5 years, however, we should expect an estimated coefficient of around 1.15 for $t \leq 100$, and a coefficient of around -2 for $t>100$. However, due to the influence of $Z_{t}$ on $Y_{t}$ at 6 years frequencies, we should expect an unbiased estimate of the influence of $X_{t}$ on $Y_{t}$ by controlling for the influence of $Z_{t}$. This experiment clearly shows that OLS estimates depend on frequencies. However, this rich and important information cannot be extracted by using standard dynamic panel or time-series approaches that exploit the information only at the time dimension. To make this last point clear, we run simple OLS regressions of the relationship between $Y_{t}, X_{t}$ and $Z_{t}$ and obtain (HAC standard errors in parentheses):

$$
Y_{t}=\underset{(0.10)}{0.02}+\underset{(0.07)}{0.30} X_{t}
$$

and

$$
Y_{t}=\underset{(0.09)}{0.02}+\underset{(0.06)}{0.28} X_{t}+\underset{(0.13)}{0.86} Z_{t} .
$$

Hence, even if we control for the influence of $Z_{t}$ in a standard OLS regression (equation (2)), we are not able to recover the fact that, first, the OLS estimates are different at different frequencies, and, second, that we observe a structural break in frequencies ${ }^{11}$.

Figure (2) in Appendix A.2 summaries our findings by employing continuous wavelets. Reflecting the respective vertical axis of each plot in figure (2) in Appendix A.2, it is worth noting that cycles of 1.5-4 years show the short end of business cycles, cycles of 4-8 years present the bulk of business cycle fluctuations, and cycles of 8-20 years capture long-run relations (see Aguiar-Conraria et al. (2018a)). Hence, our example and the analysis executed below simultaneously covers short, medium and long-run relationships. In the top (bottom) left panel, we show a so-called heat map which visualizes the non-Granger-causal (Granger-causal) relationship between $Y_{t}$ on $X_{t}{ }^{12}$. The warmer the colors, the stronger is the relationship of these two variables in the time and frequency domain.

\footnotetext{
${ }^{11}$ As we have a structural break in frequencies and not in the time dimension, a dummy-variable in equation (1) and (2) turns out to be insignificant.

${ }^{12}$ For instance, if life expectancy at birth Granger-causes income inequality, the change in life expectancy at birth comes before the change of income inequality. Thus, the lagged value of life expectancy at birth helps to predict the current values of income inequality. In turn, past values of income inequality should not have any significant impact in explaining the current variations in life expectancy at birth. Hence, we do not argue that Granger-causality implies causality, although we controlled for the influence of additional (but possibly endogenous) variables.
} 
The right panel shows the so-called wavelet gain, which is the estimated coefficient of regressing $Y_{t}$ on $X_{t}$ with and without controlling for the influence of $Z_{t}$ in absolute terms. The center panel provides us with information regarding the leading-lag relationship between $Y_{t}$ on $X_{t}$, and, hence, establishes a Granger-causal relationship between these variables at very period of time and frequency ${ }^{13}$. This center panel also helps us to identify the sign of the wavelet gain.

From this experiment, we should take on board that wavelet tools not only simultaneously extract information from the time and frequency dimension. These tools further establish a so-called Granger-causal (lead-lag) relationship. Figure (2) in Appendix A.2 makes this latter point clear: By comparing the second plot from above in the right panel with the plot at the bottom in the right panel clearly shows that the relationship between $Y_{t}$ on $X_{t}$ is measured with higher accuracy when controlling for the influence of $Z_{t}$.

We can directly link this experiment's findings to our data-set. Assume that we run the very naive OLS regression of the (stationary) growth rate of life expectancy at birth as a proxy for health on a constant and the (stationary) growth rate of the Gini-index. With our data, we would have that (HAC standard errors in parentheses):

$$
\text { health }_{t}=\underset{(0.000)}{0.003}-\underset{(0.05)}{0.009} \text { Gini }_{t},
$$

which, ignoring for a moment any further identification problems, would suggest that there is no significant relationship between income inequality and life expectancy at birth in the time dimension at given growth frequencies. However, with the continuous wavelet, we can exploit the time and frequency dimension simultaneously to check whether or not this relationship is still insignificant. Even if we would have solved any identification problems associated with estimation equation (3), we still cannot be sure that there is a(n) (in)significant Granger-causal lead-lag relationship at a specific frequency. Again, it would be nice to exploit this additional information for the design of a health policy. For instance, if short-run shocks are predominantly relevant for explaining the variance of the income-health relationship, a policy design should have a short-run focus.

In a nutshell, what we obtain by using wavelets is a time series of estimates for a band of frequencies. Stated in different words, using wavelets could be also interpreted as a robustification of pure time-series or panel data estimates, which usually ignore the frequency domain. Moreover, with a multivariate extension of the continuous wavelet, we can also establish Granger-causality in the time and frequency dimension explaining the health status-income inequality nexus.

\footnotetext{
${ }^{13}$ Olayeni (2016) offers an alternative approach to implementing the continuous wavelet transform causality.
} 


\section{Data}

We draw on annual data for the U.S. economy between 1941 and $2015^{14}$. The length of the period is dictated by the availability of the Gini-index. As a measure for health status, we include life expectancy at birth, which is in line with the health economics literature ${ }^{15}$. The life expectancy at birth (for both men and women) are available on-line from the Human Mortality Database hosted by the Max Planck Institute, Rostock, and the University of California, Berkeley (https ://www .mortality.org/). Data for the U.S. government spendings on education/health per capita and GDP per capita (constant 2012 U.S. Dollar) were retrieved from http : / us government spending . com (see also Chantrill (2012)). A frequently used measure for inequality is the Gini-index. We collect data for the annual income Gini-index (equalized gross U.S. household income) from Atkinson et al. (2017). We have calculated annual growth rates for all considered variables.

\section{Results}

\subsection{Descriptive Statistics}

Table (1) summarizes the descriptive statistics of GDP per capita (constant 2012 U.S. Dollar), GDP, the Gini index, Gini, and government spendings on education/health per capita (constant 2012 U.S. Dollar), Educ/Hspen. Descriptive statistics for the life expectancy at birth, health, is also reported for men health (male) and women, health (female).

During 1941-2015, the U.S. economy was hit by several shocks: The period of World War II (WWII) period (1939-1945), the two oil crises (1973-1975 and 1980-1982), the 1990s recession (1990-1992), the dot-com bubble recession (2001-2002), and the subprime crisis (2007-2009). After WWII, income inequality was rather stable until the 1970's where it was steadily increasing until the end of our sample in 2015. During the same time, life expectancy (for men and women) at birth increased. We further observe that government spendings on education increases after WWII and reached its speak during the second oil crisis. Educ/Hspen and GDP per capita are highly correlated (0.99/0.97). Moreover we find that the correlation between the Gini-index and life expectancy at birth is 0.75 if we do not differentiate between both sexes. If we take the sex into account, the correlation is smaller for women (0.67) than for men (0.81). Besides the fact that GDP and Educ might influence the income inequalty-health relationship, we should also control for possible gender differences with respect to their life expectancy at birth.

\footnotetext{
${ }^{14}$ Unfortunately, higher frequency data for the Gini-index and life expectancy at birth data are not available.

${ }^{15}$ In the following we use health, health status and life expectancy interchangeably.
} 
Estimating the income inequality-health relationship for the United States between 1941 and 2015: Will the relevant frequencies please stand up?

\begin{tabular}{clllll}
\hline \hline 1. Level & & \multicolumn{5}{l}{} \\
\hline Series & Mean & $S D$ & Max. & Min. & Obs. \\
\hline GDP & $30,953.97$ & $13,084.70$ & $54,208.00$ & $11,688.00$ & 75 \\
Health & 72.83 & 4.18 & 79.07 & 63.79 & 75 \\
Health (male) & 69.72 & 4.21 & 76.64 & 61.58 & 75 \\
Health (female) & 76.00 & 4.07 & 81.45 & 66.26 & 75 \\
Gini (\%) & 40.47 & 3.25 & 46.30 & 36.30 & 75 \\
Educ & $1,543.36$ & 927.89 & $3,096.30$ & 210.70 & 75 \\
Hspen & $1,314.26$ & $1,250.12$ & $4,250.20$ & 59.00 & 75 \\
\hline 2. Annual growth rate (\%) & & & & \\
\hline Series & Mean & SD & Max. & Min. & Obs. \\
\hline GDP & 2.16 & 3.78 & 17.28 & -12.80 & 74 \\
Health & 0.29 & 0.34 & 1.18 & -0.44 & 74 \\
Health (male) & 0.29 & 0.35 & 1.17 & -0.58 & 74 \\
Health (female) & 0.28 & 0.34 & 1.31 & -0.34 & 74 \\
Gini & 0.08 & 1.59 & 2.86 & -5.62 & 74 \\
Educ & 3.62 & 6.49 & 37.93 & -10.86 & 74 \\
Hspen & 6.07 & 7.93 & 55.98 & -9.78 & 74 \\
\hline \hline
\end{tabular}

Table 1: Descriptive statistics

\subsection{Wavelet power spectrum}

Figure (3) in the Appendix A.3 presents on the right the wavelet power spectra of life expectancy at birth for both male and female, GDP per capita ${ }^{16}$, and education per capita in terms of annual growth rates, respectively. On the left, figure (3) shows the annual growth rates for each variable.

For each frequency and moment, the wavelet power indicates the intensity of the variance of the time series for each frequency of cyclical oscillations. The vertical axis shows the 1.5-30 years frequency bands, the horizontal axis displays the time dimension. The so-called cone of influence (COI) identifies regions where results are affected by edge effects, and, hence, are not reliable (inter alia, see Aguiar-Conraria and Soares (2014) for more details). Thus, only regions inside the conic dashed green lines should be interpreted. Further, the white lines in the power sepctra show local maxima, whereas the black (grey) contours show the 5\% (10\%) level of significance. Further, the degree of variability of a specific variable is distinguished by a spectrum of colors, ranging from dark blue (low variability) to red (high variability).

As shown in figure (3 A), the volatility of the Gini-index is only significant at 1.5-4 years frequencies during the period from 1941 until 1953 on a $5 \%$ level. This indicates that rising income inequality in the U.S. in that period is particularly driven by short-run and medium-run shocks during WWII and after the end of the so-called New Deal policy. In fact, we see a structural change in the variance of GDP cycles right after the end of 1953 at the 1.5 years as well as, though less pronounced, at the

\footnotetext{
${ }^{16}$ In the following, we synonymously use the terms per capita and per member of working-force.
} 


\section{4-8 years frequency band.}

As can be directly seen by comparing figures ( $3 B),(3 C)$ and $(3 D)$ with each other, the wavelet power spectra of the annual growth of life expectancy at birth for the entire population are very similar. All power spectra identify significant (at the $5 \%$ significance level) volatilities of annual growth of life expectancy at birth over the periods 1941-1945 at the 1.5-4 years frequency band showing the direct influence of the WWII shock on life expectancy. Moreover, during that time, medical progress lead to advances in vaccines, penicillin and antibiotics. In turn, this leads to an increase of longevity at all ages and for both sexes. Moreover, for the period 1955-1965, particularly for men, we see significant volatilities at the 1.5-4 years frequency. An interpretation of this latter finding might be that during that time the Korean and Vietnam wars took place, both significantly affecting the longevity of U.S. American men, whereas there is no influence on the life expectancy for women. For both sexes we observe hardly any significant volatilities at the beginning of the 1980's, which may reflect the emergence of the HI-virus which jumped from the Caribbean to the U.S. around 1970 and triggered the country's AIDS epidemic. Moreover, but only for men, the shocks associated with the economic downturn at the beginning of the 1990's as well as with the most recent economic crisis likely influence longevity at 2 years frequencies. However, we should not push this interpretation very hard though, since these volatilities are hardly significant. Finally, we observe a gradual decline of the life expectancy's variance for both sexes until the end of the 1980's at 20 to 30 years frequencies. After that time period, we observe a stabilization of the life expectancy's variance. Again, this observation might be seen as a result of the medical progress during that time period that increases longevity but at a decreasing rate.

In addition, the wavelet power spectrum in figure (3 E) identifies significant (at the $5 \%$ significance level) volatilities of annual growth of GDP over the periods 1941 to 1960 at the 4-15 years frequency band. Notably, we observe a shift towards longer cycles during that period, suggesting that longerrun shocks gain more importance. Similar to the annual growth rate of the GDP, the annual growth rate of governmental education spendings exhibits significant (at the $5 \%$ significance level) volatilities during the years 1941-1965 at the 8-15 years frequency band and, moreover, for the years 19421950 , at the 1.5-4 years frequency (see figure $(3 \mathrm{~F})$ ). This at least partly reflects the influence of WWII on governmental spendings on education. For instance, the mid-century Gl bills (a kind of a domestic Marshall plan) were the largest direct scholarship program for higher education in the U.S. history. From this perspective, it is not surprising that the wavelet power spectra of the GDP and governmental education spendings looks similar in this period.

Finally, the wavelet power spectrum in figure $(3 \mathrm{~F})$ nicely reflects the history of public health spendings in the U.S. ${ }^{17}$. Before the Medicare and Medicaid became effective on July 1, 1966, health expenditures were financed largely by private payers. From 1966 to 1973, we observe a sharp increase of the growth rate of public health spendings. This corresponds to highly significant volatilities

\footnotetext{
${ }^{17}$ See Kirby and Kaneda (2010) who provide a nice introduction to the system of health insurance coverage in the U.S..
} 
at the upper and lower bound of business cycle frequencies at the wavelet power spectrum. Thus, the increase of public health spendings between 1966 and 1973 was not only a short- but also a medium-run phenomenon. Moreover, the most important driving force for the increase in real per capita health expenditures which can be observed since 1947 is the availability of new medical technology and the increased specialization that accompanies it (Pauly (2005)). That is why we observe also significant volatilities at very long-run frequencies at least until the year 1982. In this time period, spendings for hospital care and physicians received a boost from the Medicare and Medicaid program (Fuchs (2012)).

\subsection{Health and income inequality: Is there a causal (lead-lag) relationship in time and frequency?}

In this section, we asses the relationship between health status and the income Gini-index as a measure for income inequality controlling for governmental spendings on education and health as well as for GDP in the time-frequency domain referring to multivariate continuous wavelet tools introduced in section (3). The inclusion of education/health spendings and GDP is motivated by the fact that these variables are likely to affect simultaneously the health status as well as income inequality, particularly on an aggregate level.

To obtain a first impression regarding the cyclical relationship between health and inequality, we first start with the computation of the simple coherence between health and inequality. Next, we present and discuss the partial coherency, the partial phase-difference, and, finally, the partial gain between life expectancy at birth and the Gini-index for income by controlling for the influences from GDP and governmental spendings for health and education ${ }^{18}$. As already mentioned above, the partial gain delivers the regression coefficient of a regression of life expectancy at birth on the Gini-index for income by controlling for the influences stemming from governmental spendings on education and health as well as from aggregate income. Figures (4)-(6) in Appendices A.4-A.6 summarize our findings. From the wavelet power spectrum analysis above (section 5.2), we obtain the impression that short- but even longer-run frequencies are relevant. Hence, in the following we focus on the 1.5-15 years frequency as well as on the 15-30 years frequency band.

To facilitate the presentation, we follow the suggestion made by $\mathrm{Ge}$ (2008) and only focus on the mean values of the phase-differences with corresponding statistically significant coherencies ${ }^{19}$. We start with the simple coherency graphically depicted in figure (4) that shows a simple bivariate relationship between life expectancy at birth and the Gini-index. Only for the longer-run frequencies (20-30 years), we observe a pronounced, significant, bi-variate relationship between health status and income inequality ranging over the entire sample size (excluding the cone of influence). More-

\footnotetext{
${ }^{18}$ To ensure readability, we depart from mentioning that variables are measured in growth rates.

${ }^{19}$ We do note compute corresponding confidence intervals. Reflecting the relevant literature, it is challenging to formulate a Null hypothesis that is not too restrictive for an economic model (inter alia, see Aguiar-Conraria (2018b), Ge (2007, 2008) and Maraun et al. (2007))).
} 
over, we observe some very short periods where there is also a highly significant relationship between health status and income inequality at business cycle frequencies. Interestingly, these periods comprise the recessions in 1953, 1969 as well as the great recession between December 2007-June 2009. Nevertheless, the fact that in figure (3) cold colors prevail indicates a low level of significant coherence (at the $5 \%$ significance level) for the great majority of frequencies over the years 1941 2015. However, an obvious drawback associated with the simple coherency is that we cannot isolate a potential impact of other variables on the income inequality-health relationship. Hence, next we estimate the partial coherence between life expectancy at birth and the Gini-index, controlling for the influence coming from GDP and governmental spendings on education and health (see lower left panel in figure (4)).

The inclusion of the control variables dramatically changes our findings. First, we observe a relatively pronounced high level of significant coherence (at the 5\% significance level) at the 20 years frequency band for the time span 1956-1993. Second, for the years 1947-1950, we see a significant relation between the health status and income inequality at the 2-4 years frequency band. This is also true for the the years 1959-1977 at the 3-4 years frequency band as well as for the time span 1983-1995. Finally, for the years 2006-2007, we observe a highly significant relation at the 2-4 years frequency band. Compared to the findings derived from the simple coherency, after including the controls, we see that some frequencies lose importance explaining the health-income inequality relationship, whereas other frequencies become more dominant, particularly at the 3-13 years frequencies.

What remains robust is the health-income inequality relationship at the long-run. After the inclusion of controls, this relationship is only significant at a 5\% level in the period between 1956-1993 at the 15-20 years frequency band. From a pure time-series perspective, this latter result is less surprisingly, as income inequality and life expectancy at birth rates are generally considered as slow-moving processes. For the remaining frequencies, the picture is somewhat unclear. Although we observe some significant relationships at higher frequencies, these relationships are rather short-lived, and, might be therefore interpreted as short-run deviations from a stable health-income inequality relationship in the longer-run, at least until the year 1993. After the year 1993, if any, only very short-lived periods of a significant relationship between health status and income inequality can be observed at higher frequencies (1.5-10 years).

The innovation of this paper is that we can be more precise regarding the description of the coevolution of the health-income inequality relationship by calculating the partial gain and interpret the results together with the partial phase-differences for specific frequency bands. The result of this exercise can be found in the middle and right panel in figure (4). For the years 1956-1993, health status and income inequality move out of phase at long-run frequencies (15-20 years) as indicated by the partial phase-difference that is between $\left[\frac{\pi}{2}, \pi\right]$. In turn, this implies a negative relationship between health status and inequality, where the Gini-index is the leading variable. Moreover, over this period, the gain is steadily decreasing from 0.09 to 0.06 . Thus, for the period 1956-1993 and 
for longer frequencies, we can confirm the existence of an $\mathrm{IIH}$ as an increase of income inequality has adverse health effects, although the IIH becomes weaker until 1993 and completely disappears afterwards as indicated by the decreasing gain. Controlling for gender do not alter the overall findings we made above regarding the existence of the $\mathrm{IIH}$. However, we find that the health-income inequality relationship is more pronounced for men than for women (see figure (5) and (6) in the Appendix). Finally, we have also checked whether our results are robust regarding the measure of income inequality. We have used the share of top $1 \%$ in gross income (tax units, excluding capital gains) as an alternative indicator for income inequality ${ }^{20}$. Comparing figure (7) with figure (4), we do not find qualitatively different results.

The overall important impression we can take on board from this exercise is that an increase in income inequality has adverse health effects only at longer-run frequencies and only for the years 1956-1993, thus confirming the existence of an IIH. Considering the entire time span over all observed frequencies, however, the evidence for a potential existence of an IIH is rather weak, particularly after 1993.

\section{Discussion}

This section is devoted to a discussion of our findings in the light of established literature. A central result we derive from our analysis is that our wavelet analysis predicts a strong relationship between income inequality and health status only at longer-run frequencies and only between 1956-1993. We also see that to some extent the correlation between income inequality and health status reflects more the operation of some third, neglected factors, such as governmental spendings for education (see Grossman $(1972,1975,2000)$ ) and health rather than a causal link (e.g. see Deaton (2003)) at least in the long-run and prior 1986. In the light of our findings, the IIH is the rare exemption rather than the rule. From this point of view, it is not astonishing that Mellor and Milyo's (2001, 2002), who tried to reproduce the findings made by Wilkinson (1992), find a non-significant correlation coefficient between between changes in both income inequality and life expectancy between 1970 and 1980 . Their results are partly reflected by our findings. Although we find a positive correlation in the long-run in that time, according to the evolution of the computed gain, the correlation is nevertheless weak.

But why does the link between health status and income-inequality has decreased between 19561993 and disappeared afterwards, at least at longer-run cycles? As already mentioned, from 1966 to 1973 , we observe a sharp increase of the growth rate of public health spendings. Fuchs (2012) pointed out that between 1950 and 1980, spendings for hospital care and physicians received a boost from the Medicare and Medicaid program. Together with the medical technological progress in these time this might explain the increase of people's longevity. What we also see in the data is that after 1972, income inequality in the U.S. increased, with an accelerating rate in the mid-1980's.

\footnotetext{
${ }^{20}$ Data are available from from Atkinson et al. (2017). Due to data limitations, we cannot use other indicators for income inequality.
} 
Prior to 1972 , where real median family incomes grew, we observe that income inequality shows no perceptible trend after it slightly fell between 1941-1971 (Deaton and Paxson (2004)). In contrast, the increase of longevity in the U.S. continued even after the mid-1980's, while family incomes fell. In line with our findings, there is no significant link between longevity and long-run income inequality after the year 1993 and, moreover, we expect that the link becomes weaker the closer we move to the year 1993. What is nevertheless interesting though, is our finding that the significant relationship between health and income inequality between the years 1956-1993 is relatively more pronounced for men than for women which might be explained by their different histories of health behavior (see Wise (2004)).

Moreover, for higher frequencies (1.5-8 years) and more recent times, we do not find clear evidence for a the existence of the $\mathrm{IIH}$. Interestingly, for the time span 2003-2008 which also comprises the subprime crisis as well as the epidemic of pain, suicide and drug (Case and Deaton (2015)), we observe an unclear lead-lag relationship between health status and income inequality. This finding leaves us with the impression that for the periods after 2007, for neither frequency domain we observe a significant relationship between health status and income inequality.

Of course, and the reader should keep this in mind, our findings do not imply that there is no way to establish a potential causal relationship between health status and income inequality. Income inequality evolution can be seen as a consequence of, among others, social, political and economic shocks hitting the U.S. economy differently at the time and frequency domain. Controlling for any underlying factors which simultaneously determine health and income inequality is, of course, impossible $^{21}$. What we can say is that what many researchers in the literature claim to be causal is in fact, if at all, a rare exemption, even if we investigate this relationship in time and frequency.

What are the caveats of our study? Rodgers (1979) and Gravelle (1998) pointed to the fact that if individual health is a nonlinear function of income, income inequality may be spuriously correlated with aggregate health status. As we use aggregate data, our results might partly suffer from a potential ecological fallacy, which we obviously cannot resolve by using aggregate data. This implies that aggregate correlations do not necessarily reflect (Granger-) causal relationships at the individual level. Mellor and Milyo (2001) tackle exactly this issue. Using data from 1995-1999, the authors find no evidence of an association between income inequality and health status at the U.S. metropolitan area level.

Closely related to the first caveat, we cannot control for the fact that income inequality might affect health inequality on a sub-national level, even if it does not affect average health. As mentioned by Kawachi et al. (2002), poverty besides many other characteristics may not only impact the average health of a community, but also affects health disparities between social groups. What we see in our data is that for the recent years, national mortality rates are rather stable over time, which shows

\footnotetext{
${ }^{21}$ As an example, among others, such factors comprise changes in manufacturing employment, international migration, urbanization in specific areas, and the increase of households headed by single females or technological progress in the health sector.
} 
that sub-national health disparities seem to channel out on a national level. So even if we observe that health inequality affects sub-national health inequality via the income channel, we do not necessarily observe that on a national level, where average health seems to be rather constant over time. Again this highlights the important findings made by Chetty et al. (2016) that the differences in life expectancy were correlated with health behaviors and local area characteristics.

But even on the aggregate level, it might be that income inequality can still affect health inequality even if it does not directly affect health ${ }^{22}$. From a city-level perspective, this might be explained by local governmental expenditures schemes and also partly by positive neighborhood externalities. Supported by the data, low-income individuals tend to live longest in cities with highly educated people and high governmental expenditures for public health and educational spendings (see Chetty et al. (2016).). After aggregation to the city-level, we might conjecture that, first, in those cities, the correlation between city-level income inequality and city-level health status should be lower compared to other cities where governmental expenditure activities are less pronounced. In turn, this might also explain that some cities with higher income inequalities exhibit lower levels of health inequalities (even if there is no correlation between the city-level income inequality and city-level health status after controlling for governmental spendings and neighborhood effects). Beyond the scope of this paper, testing this theory may be a good subject for future research in this area.

Further, our time span comprises several crisis periods which might also affect the incomeinequality health relationship. For instance, to maintain a rising standard of living, particularly households in the lower part of the distribution finance their spendings at the cost of increasing their debt level ${ }^{23}$. During the crisis, these households cut spendings (including health spendings), shed outstanding debts, and increased their rate of personal savings in response to reductions in income.

Finally, the concept of Granger-causality based on the lead-lag relationship between life expectancy at birth and income inequality is only a necessary condition for the true causality between life expectancy at birth and income inequality. Hence, we cannot exclude the possibility, and of course, do not argue that the relationship between life expectancy at birth and income inequality is driven by other variables which are not included here. The choice of our controls is primarily motivated by the literature (among others, see Barro (2013), Mellor and Milyo (2001)). Instead, our results provide information regarding a possible lead-lag pattern of two variables over a certain time period and frequency.

\section{Conclusion}

The income inequality hypothesis predicts that income inequality itself is the major determinant of population health. Using cross-section or longitudinal approaches, there is an enormous literature

\footnotetext{
${ }^{22} \mathrm{We}$ are grateful to a referee for pointing us to this issue.

${ }^{23}$ As shown by Cairó and Sim (2017), for the U.S., between 1960 and 2010, there is a close link between income inequality and credit-to-GDP ratio, which, in turn can be seen as a good indicator of excessive credit.
} 
trying to establish such a link empirically. While earlier studies predict a strong causal relationship between income inequality and health, recent contributions, taking the bidirectional causality between health and income inequality into account, are very skeptical about finding support of the IIH for the U.S.. This paper argues that the so-far neglected frequency domain might render this overall conclusion. Using annual data for the U.S. between 1941-2015, a novel continuous wavelet approach allows us to estimate the $\mathrm{IH}$ relationship at any frequency and time domain. After controlling for gender, aggregate income, governmental spendings on health and education, only for the time span 1956-1993 and only for long-run frequencies, we find that an increase of income inequality has adverse effects on health, thus confirming the existence of the $\mathrm{IIH}$. However, we fail to confirm its existence for shorter frequencies at the same period, which comprises also the business-cycle frequencies, but also for other periods at different short-as well as long-run frequencies. Hence, the empirical confirmation of the $\mathrm{IIH}$ is the rare exemption rather than the rule.

\section{Declarations of interest:}

None 


\section{References}

Aguiar-Conraria, L., P. C. Magalhães and M. J. Soares (2012): Cycles in Politics: Wavelet Analysis of Political Time Series. American Journal of Political Science, 56, pp. 500-518.

Aguiar-Conraria, L., P. C. Magalhães and M. J. Soares (2013): The nationalization of electoral cycles in the United States: a wavelet analysis. Public Choice, 156, pp. 387-408.

Aguiar-Conraria, L. and M. J. Soares (2014): The Continuous Wavelet Transform: moving beyond uni- and bivariate analysis. Journal of Economic Surveys, 28, pp. 344-375.

Aguiar-Conraria, L., Manuel M.F. Martins and M. J. Soares (2018a): Estimating the Taylor rule in the time-frequency domain. Journal of Macroeconomics, 57, pp. 122-137.

Aguiar-Conraria, L., Manuel M.F. Martins and M. J. Soares (2018b): California's carbon market and energy prices: a wavelet analysis. Philosophical Transactions of the Royal Society A: Mathematical, Physical and Engineering Sciences, 376. Doi: /10.1098/rsta.2017.0256

Atkionson, A.B., J. Hasell, S. Morelli and M. Roser (2017): The Chartbook of Economic Inequality.

Babones, S. J. (2008): Income inequality and population health: correlation and causality. Social Science and Medicine, 66, pp. 1614-1626.

Bago d'Uva, T.M., O.A. O'Donnell and E.K.A. van Doorslaer (2008): Differential health reporting by education level and its impact on the measurement of health inequalities among older Europeans. International Journal of Epidemiology, 37, pp. 1375-1383.

Barro, R. J. (2013): Health and Economic Growth. Annals of Economics and Finance, 14, pp. 305-342.

Beckfield, J. (2004): Does Income Inequality Harm Health? New Cross-National Evidence. Journal of Health and Social Behavior 45, pp. 231-248.

Beckfield, J., S. Olafsdottir, and E. Bakhtiari (2013): Health Inequalities in Global Context. American Behavioral Scientist, 57, pp. 1014-1039.

Bloomfield, D., R. McAteer, B. Lites, P. Judge, M. Mathioudakis, and F. Keena (2004): Wavelet Phase Coherence Analysis: Application to a Quiet-Sun Magnetic Element. The Astrophysical Journal, 617, pp. 623-632.

Cairó, I. and J. Sim (2017): Income Inequality, Financial Crises and Monetary Policy. mimeo.

Chantrill, C. (2012): US government spending: history, facts and charts of spending, taxes and debt, federal, state and local, election 2012 special edition. Seattle 
Case, A. and A. Deaton (2015): Rising morbidity and mortality in midlife among white non-Hispanic Americans in the 21st century. Proceedings of the National Academy of Sciences of the United States of America, 112, pp. 15078-15083.

Chen, W.-Y. (2017): Health progress and economic growth in the USA: the continuous wavelet analysis. Empirical Economics, 50, pp. 8312-855.

Chetty, R., M. Stepner, S. Abraham, S. Lin, B. Scuderi, N. Turner, A. Bergeron, and D. Cutler (2016): The Association Between Income and Life Expectancy in the United States, 20012014. Journal of the American Medical Association, 315, pp. 1750-1766.

Clarkwest, A. and C. Jencks (2003): Inequality and Mortality in Rich Countries: Who Owns the Null Hypothesis? Working paper. Cambridge, MA: John F. Kennedy School of Government, Harvard University.

Cutler, D. M., A. Deaton, and A. Lleras-Muney (2006): The Determinants of Mortality. Journal of Economic Perspectives, 20, pp. 97-120.

Deaton, A. (2003): Health, Inequality, and Economic Development. Journal of Economic Literature, 41, pp. 113-158.

Deaton, A. and C. Paxson (2004): Mortality, Income and Income Inequality over Time in Britain and the United States. In: D.A. Wise (ed.), Perspectives on the Economics of Ageing. Chicago: University of Chicago Press, pp. 247-280.

Engle, R.F. (1976): Interpreting spectral analyses in terms of time-domain models. Annals of Economic and Social Measurement, 5, pp. 89-109.

Flegg, A.T. (1982): Inequality of income, illiteracy and medical care as determinants of infant mortality in underdeveloped countries. Population Studies, 36, pp. 441-458.

Flor, M. and T. Klarl (2017): On the Cyclicity of Regional House Prices: New Evidence for U.S. Metropolitan Statistical Areas. Journal of Economic Dynamics and Control, 77, pp. 134-156.

Francovic, I. and Kuhn, M. (2019): Access to health care, medical progress and the emergence of the longevity gap: A general equilibrium analysis. The Journal of the Economics of Ageing (forthcoming).

Fuchs, V.R. (2012): Major Trends in the U.S. Health Economy since 1950. The New England Journal of Medicine, 366, pp. 973-977.

Gerdtham, U.-G. and M. Johannesson (2005): Business Cycles and Mortality: Results from Swedish Micro Data. Social Science and Medicine, 60, pp. 205-218. 
Garcia Gomez, M.P., J.L.W. van Kippersluis, O.A. O'Donnell and E.K.A. van Doorslaer (2013). Long Term and Spillover Effects of Health Shocks on Employment and Income. Journal of Human Resources, 48, pp. 873-909.

$\mathrm{Ge}$, Z. (2007). Significance tests for the wavelet power and the wavelet power spectrum. Annals of Geophysics, 25, pp. 2259-2269.

Ge, Z. (2008): Significance tests for the wavelet cross spectrum and wavelet linear coherence, Annals Geophysicae, 26, pp. 3819-3829.

Glied, S. and A. Lleras-Muney (2008): Technological innovation and inequality in health. Demography, 45, pp. 741-761.

Gravelle, H. (1998): How Much of the Relation Between Population Mortality and Unequal Distribution of Income is a Statistical Artefact? British Medical Journal, 316, pp. 382-85.

Grossman, M. (1972): On the Concept of Health Capital and the Demand for Health. Journal of Political Economics, 80, pp. 223-55.

Grossman, M. (1975): The Correlation between Health and Schooling. In: Nestor Terleckyj (ed.), Household Production and Consumption. Columbia University Press for NBER, pp. 147-211.

Grossman, M. (2000): The Human Capital Model. In: Anthony J. Culyer and Joseph P. Newhouse (eds.), Handbook of Health Economics, Vol. 1A, Amsterdam: Elsevier, pp. 347-408.

Hollingsworth, A., C. Ruhm and K. Simon (2017): Macroeconomic conditions and opioid abuse. Journal of Health Economics, 5, pp. 222-233.

Judge, K. (1995): Income Distribution and Life Expectancy: A Critical Appraisal. British Medical Journal, 311, pp. 1282-85.

Judge, K., J.-A. Mulligan, and M. Benzeval (1998): Income Inequality and Population Health. Social Science and Medicine, 46, pp. 567-79.

Kaplan, G. A., E.R. Pamuk, J.M. Lynch, R.D. Cohen, and J. L. Balfour (1996): Inequality in Income and Mortality in the United States: Analysis of Mortality and Potential Pathways. British Medical Journal, 312, pp. 999-1003.

Kawachi, I., B.P. Kennedy, K. Lochner, and D. Prothrow-Stith (1997a): Social Capital, Income Inequality, and Mortality. American Journal of Public Health, 87, pp. 1491-1499.

Kawachi, I., B.P. Kennedy and Kimberly Lochner (1997b): Long Live Community: Social Capital as Public Health. The American Prospect, 35, (November/December), pp. 56-59. 
Kawachi I, S.V. Subramanian and N. Almeida-Filho (2002): A glossary for health inequalities. Journal of Epidemiology and Community Health, 56, pp. 647-52.

Kirby, J.B. and T. Kaneda (2010): Unhealthy and uninsured: Exploring racial differences in health and health insurance coverage using a life table approach. Demography, 47, pp. 1035-1051.

Klarl, T. (2016): The nexus between Housing and GDP re-visited: A wavelet coherence view on Housing and GDP for the U.S.. Economics Bulletin, 36, pp. 704-720.

Ko, J.-H. and C-M. Lee (2015): International economic policy uncertainty and stock prices: Wavelet approach. Economics Letters, 134, pp. 118-122.

Lam, J.-P. and E. Piérard (2017): The Time-Varying Relationship between Mortality and Business Cycles in the USA. Health Economics, 26, pp. 164-183.

Leigh, A., C. Jencks and T.M. Smeeding (2009): Health and Economic Inequality. In W. Salverda, B. Nolan and T.M. Smeeding (eds.) The Oxford Handbook of Economic Inequality, pp. 384-405, Oxford University Press, Oxford.

Lynch, J. and G.A. Kaplan (1997): Understanding How Inequality in the Distribution of Income Affects Health. Journal of Health Psychology, 2, pp. 297-314.

Lynch, J., G.A. Kaplan, E.R. Pamuk, R.D. Cohen, K.F. Heck, J.L. Balfour and I.H. Yen (1998): Income Inequality and Mortality in Metropolitan Areas of the United States. American Journal of Public Health, 88, pp. 1074-1080.

Lynch, J., G.D. Smith, S. Harper, M. Hillemeier, N. Ross, G. Kaplan and M. Wolfson (2004): Is Income Inequality a Determinant of Population Health? Part 1: a Systematic Review. Millbank Quarterly, 82, pp. 5-99.

Mandler, M. and M. Scharnagl (2014): Money Growth and Consumer Price Inflation in the Euro Area: A Wavelet Analysis. Bundesbank Discussion Paper No. 33/2014.

Maraun, D., Kurths, J., and Holschneider, M. (2007): Non-stationary Gaussian processes in wavelet domain: definitions, estimation and significance testing, Physical Review E, 75, 016707.

Meltzer, A. H. and Richard, S. F. (1981): A Rational Theory of the Size of Government. Journal of Political Economy, 89, pp. 914-927.

Mellor, J.M., and J. Milyo (2001): Reexamining the Evidence of an Ecological Association between Income Inequality and Health. Journal of Health Politics, Policy and Law, 26, pp. 487-522.

Mellor, J.M., and J. Milyo (2002): Income Inequality and Health Status in the United States: Evidence from the Current Population Survey. The Journal of Human Resources, 37, pp. 510-539. 
Olayeni, O.R. (2016): Causality in Continuous Wavelet Transform Without Spectral Matrix Factorization: Theory and Application. Computational Economics, 47, pp. 321-340.

Pauly, M.V. (2005): Competition and new technology. Health Affairs, 24, pp. 1523-1535.

Rodgers, G.B. (1979): Income and inequality as determinants of mortality: An international crosssection analysis. Population Studies, 33, pp. 343-351.

Ruhm, C.J. (2000): Are Recessions Good For Your Health? Quarterly Journal of Economics, 115, pp. 617-650.

Ruhm, C.J. (2003): Good Times Make You Sick. Journal of Health Economics, 24, pp. 637-658.

Ruhm, C.J. (2005): Mortality Increases During Economic Upturns, International Journal of Epidemiology, 34, pp. 1206-1211.

Svensson, M. and N.A. Krüger (2012): Mortality and economic fluctuations. Journal of Population Economics, 25, pp. 1215-1235.

Swift, R. (2011): The relationship between health and GDP in OECD countries in the very long. Health Economics, 20, pp. 306-322.

Torre, R. and M. Myrskylä. (2014): Income inequality and population health: An analysis of panel data for 21 developed countries, 1975-2006. Population Studies, 68, pp. 11-13.

Truesdale and Jencks (2016): The health effects of income inequality: averages and disparities. Annual Review of Public Health, 37, pp. 413-430.

van den Berg, G.J., U.G. Gerdtham, S. von Hinke, M. Lindeboom, J. Lissdaniels, J. Sundquist and K. Sundquist (2017): Mortality and the business cycle: Evidence from individual and aggregated data. Journal of Health Economics, 56, pp. 61-70.

Verona, F. (2019): Investment, Tobin's Q, and Cash Flow Across Time and Frequencies. Oxford Bulletin of Economics and Statistics. Doi: 10.1111/obes.12321

Wilkinson, R.G. (1992): Income Distribution and Life Expectancy. British Medical Journal, 304, pp. 165-168.

Wilkinson, R.G. (1996): Unhealthy Societies: The Afflictions of Inequality. London and New York, Routledge.

Zar, J. H. (1996): Biostatistical Analysis (3rd Ed.), Prentice-Hall. Upper Saddle River, New Jersey.

Zheng, H. (2012): Do People Die from Income Inequality of A Decade Ago? Social Science \& Medicine, 75, pp. 36-45. 
Estimating the income inequality-health relationship for the United States between 1941 and 2015: Will the relevant frequencies please stand up?

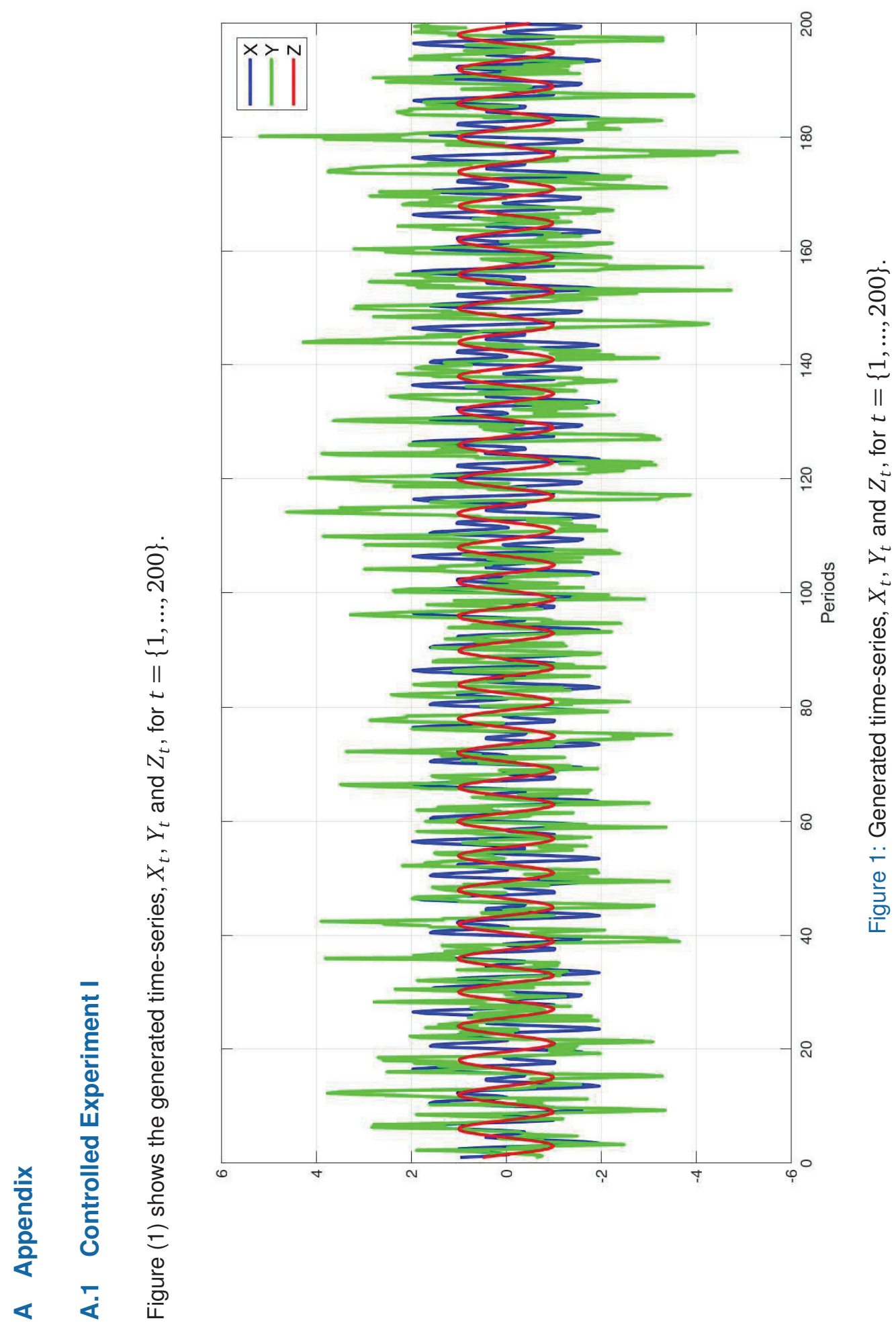




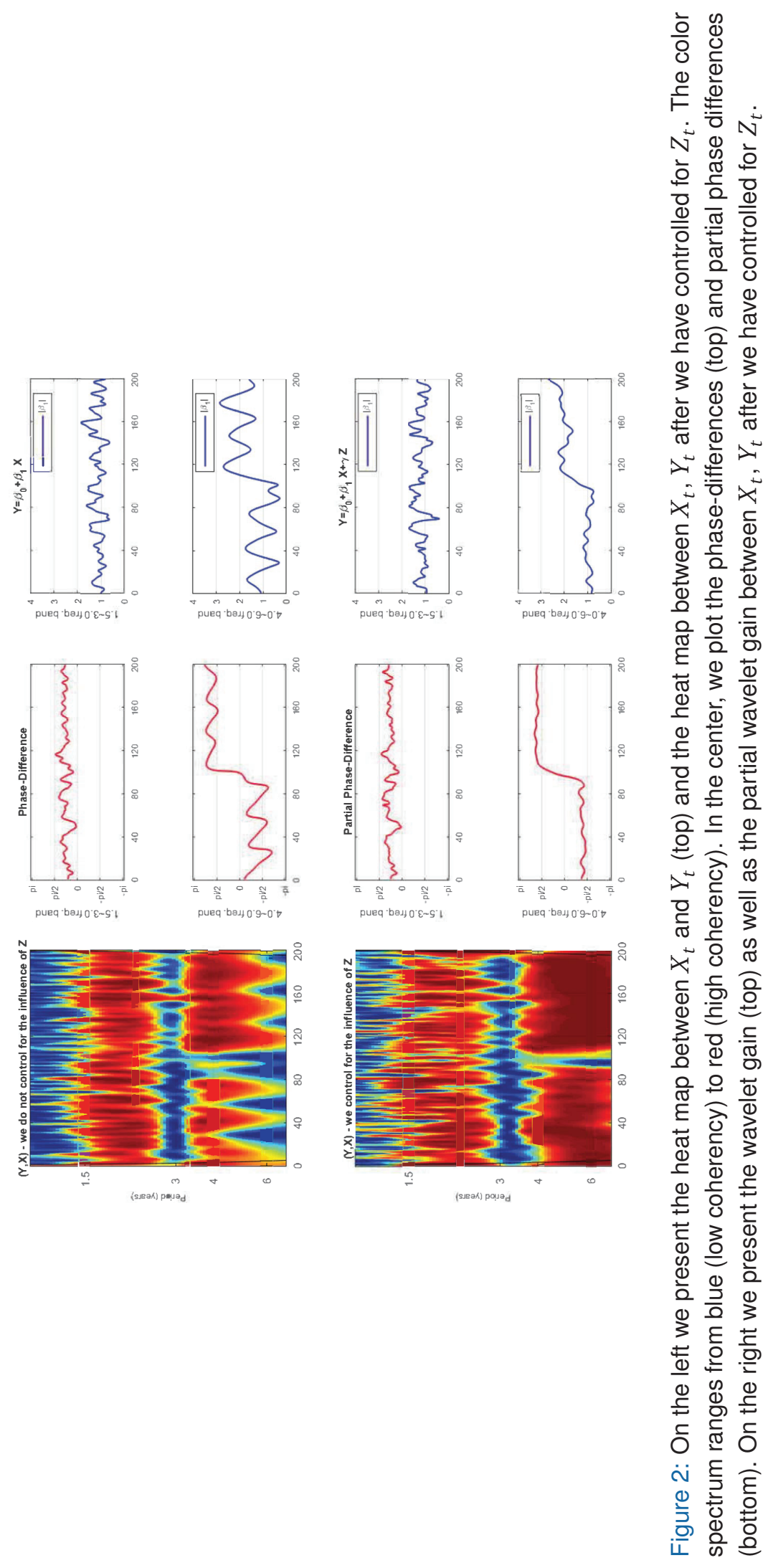




\section{A.3 Wavelet power spectrum and time-series}
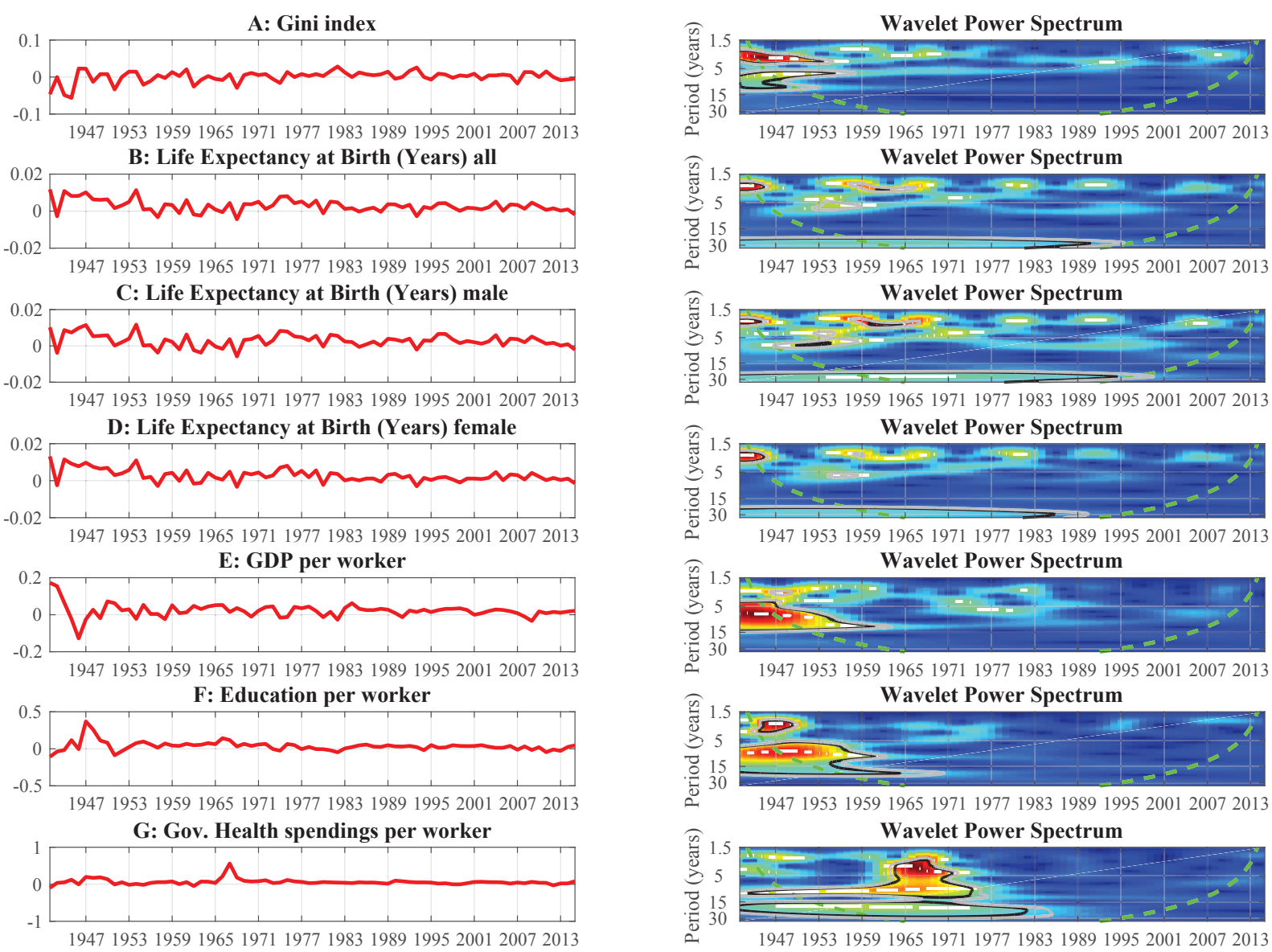

Figure 3: On the left we plot the annual growth rates of each time-series. On the right we present the wavelet power spectrum for each variable. The black (grey) contour lines indicates the 5\% (10\%) level of significance estimated by Monte Carlo simulations (5,000 draws). The coherency color spectrum ranges from blue (low coherency) to red (high coherency). The cone of influence, which shows the region affected by so-called edge effects, is the outside region of the thick-dashed, green line. 
Estimating the income inequality-health relationship for the United States between 1941 and 2015: Will the relevant frequencies please stand up?

\section{A.4 Wavelet power spectrum}
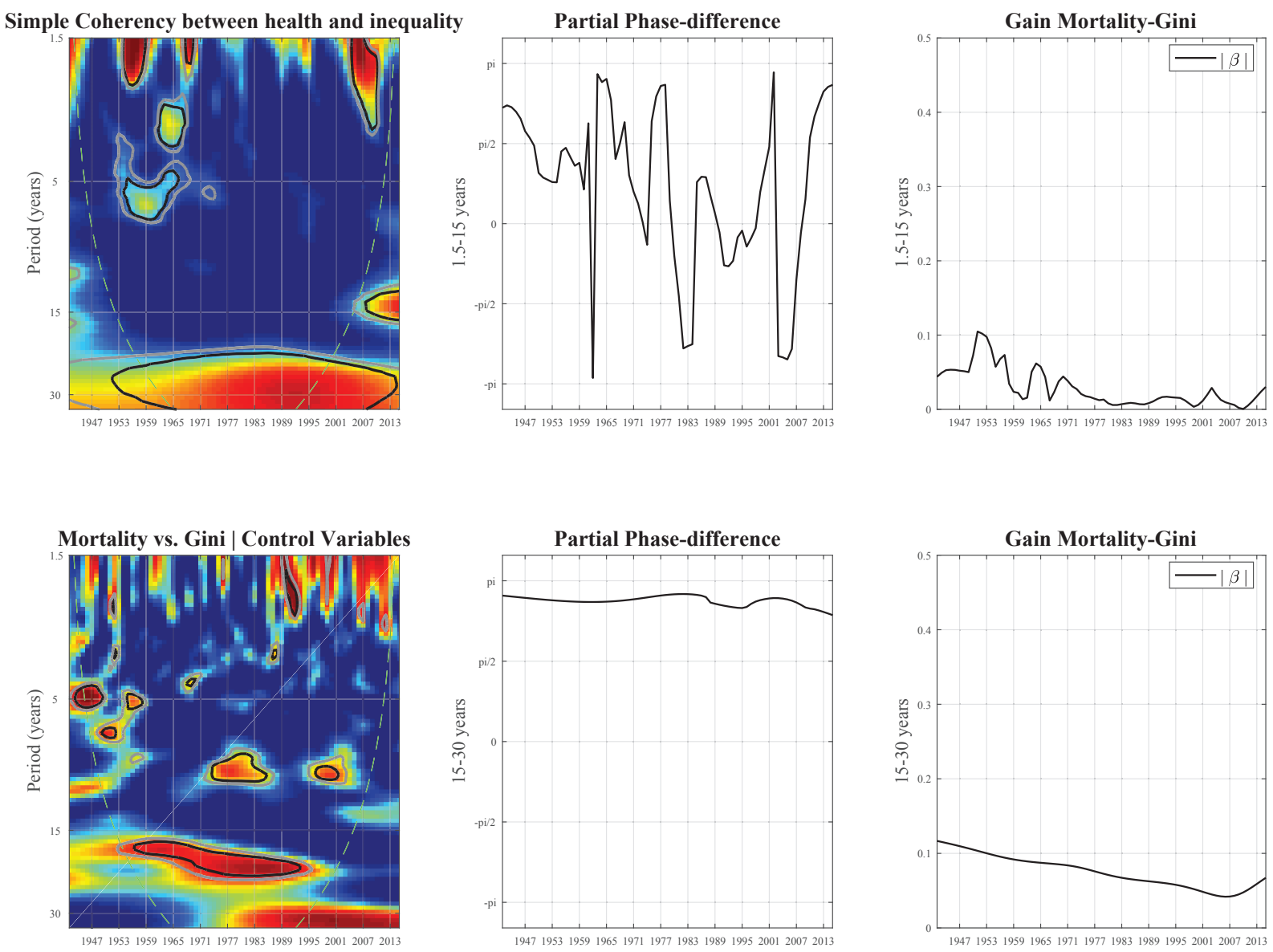

Figure 4: On the left we plot the simple wavelet coherency (top) and partial wavelet coherency between life expectancy at birth and income inequality. The black (gray) contour designates the $5 \%$ (10\%) significance level estimated by Monte Carlo simulations (5,000 draws). The color for coherency ranges from blue (low coherency) to red (high coherency). The cone of influence, which shows the region affected by so-called edge effects, is the outside region of the thick-dashed, green line. In the center we present the partial phase-differences at different frequency bands. The limits of the confidence intervals for the mean phases are indicated in the pictures with red dashed-lines. On the right we plot the partial wavelet gain at different frequency bands. 
Estimating the income inequality-health relationship for the United States between 1941 and 2015: Will the relevant frequencies please stand up?

\section{A.5 Wavelet power spectrum (female)}
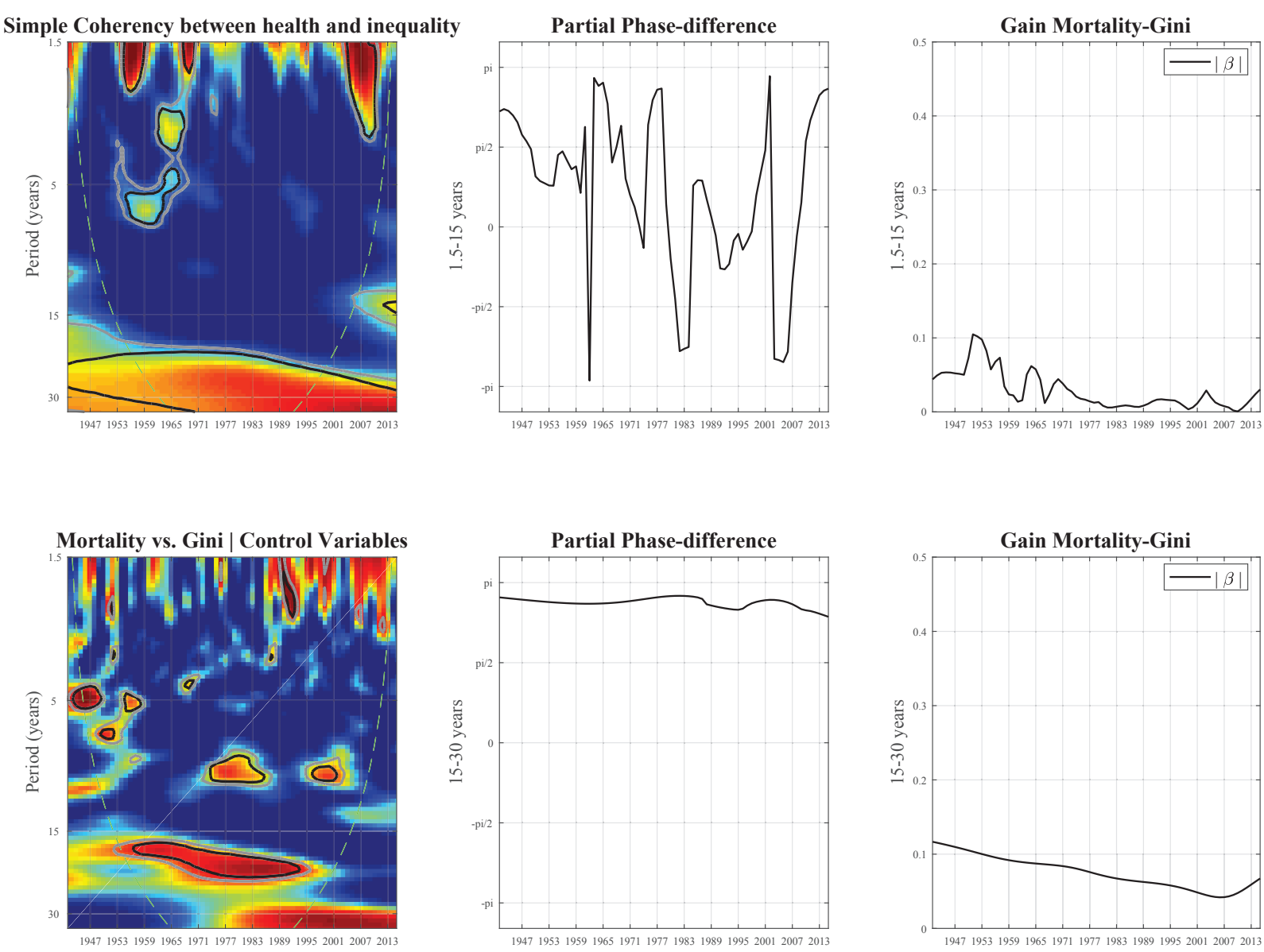

Figure 5: On the left we plot the simple wavelet coherency (top) and partial wavelet coherency between life expectancy at birth and income inequality. The black (gray) contour designates the $5 \%$ (10\%) significance level estimated by Monte Carlo simulations (5,000 draws). The color for coherency ranges from blue (low coherency) to red (high coherency). The cone of influence, which shows the region affected by so-called edge effects, is the outside region of the thick-dashed, green line. In the center we present the partial phase-differences at different frequency bands. The limits of the confidence intervals for the mean phases are indicated in the pictures with red dashed-lines. On the right we plot the partial wavelet gain at different frequency bands. 
Estimating the income inequality-health relationship for the United States between 1941 and 2015: Will the relevant frequencies please stand up?

\section{A.6 Wavelet power spectrum (male)}
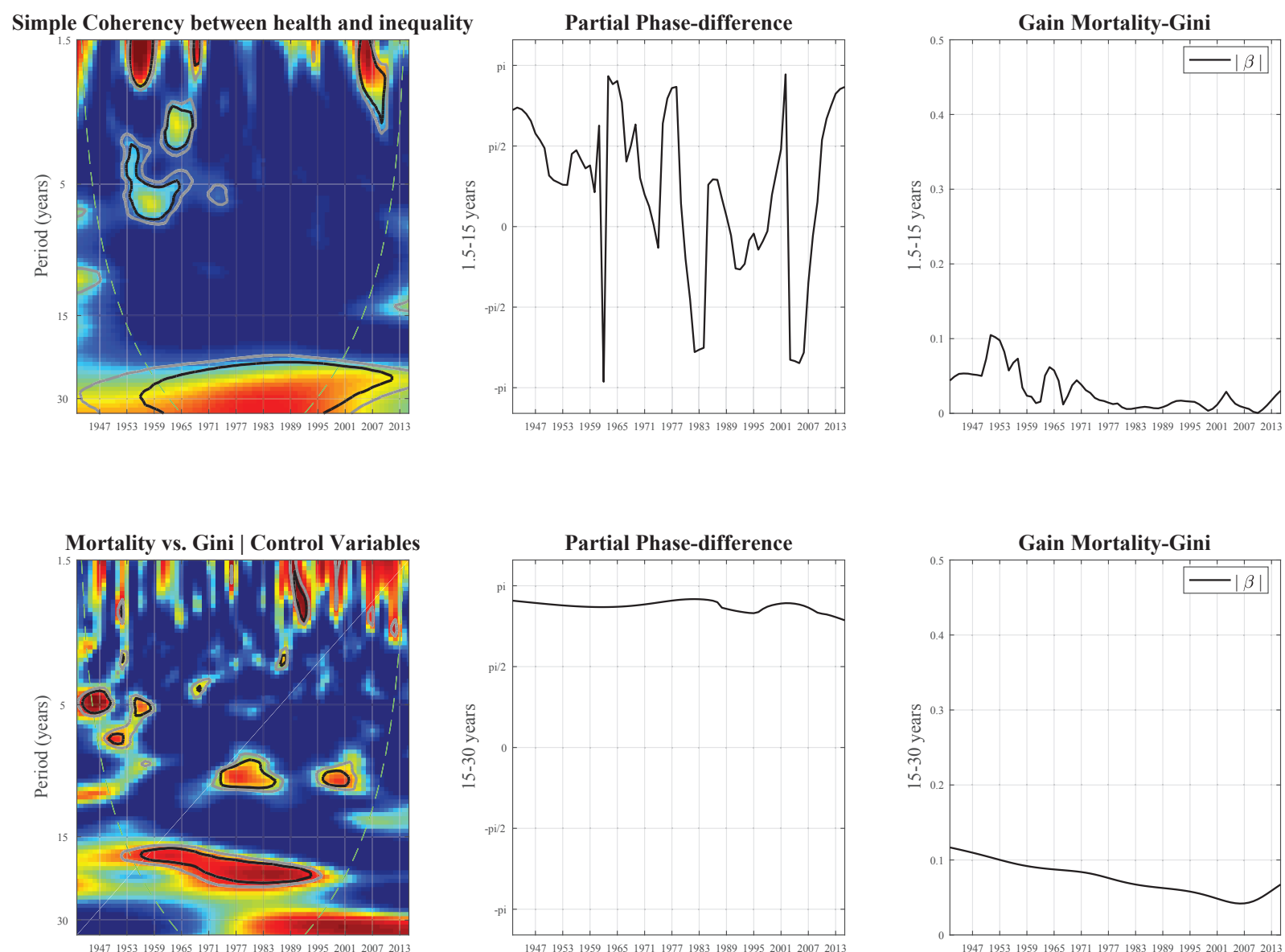

Figure 6: On the left we plot the simple wavelet coherency (top) and partial wavelet coherency between life expectancy at birth and income inequality. The black (gray) contour designates the 5\% (10\%) significance level estimated by Monte Carlo simulations (5,000 draws). The color for coherency ranges from blue (low coherency) to red (high coherency). The cone of influence, which shows the region affected by so-called edge effects, is the outside region of the thick-dashed, green line. In the center we present the partial phase-differences at different frequency bands. The limits of the confidence intervals for the mean phases are indicated in the pictures with red dashed-lines. On the right we plot the partial wavelet gain at different frequency bands. 
Estimating the income inequality-health relationship for the United States between 1941 and 2015: Will the relevant frequencies please stand up?

\section{A.7 Robustness check}
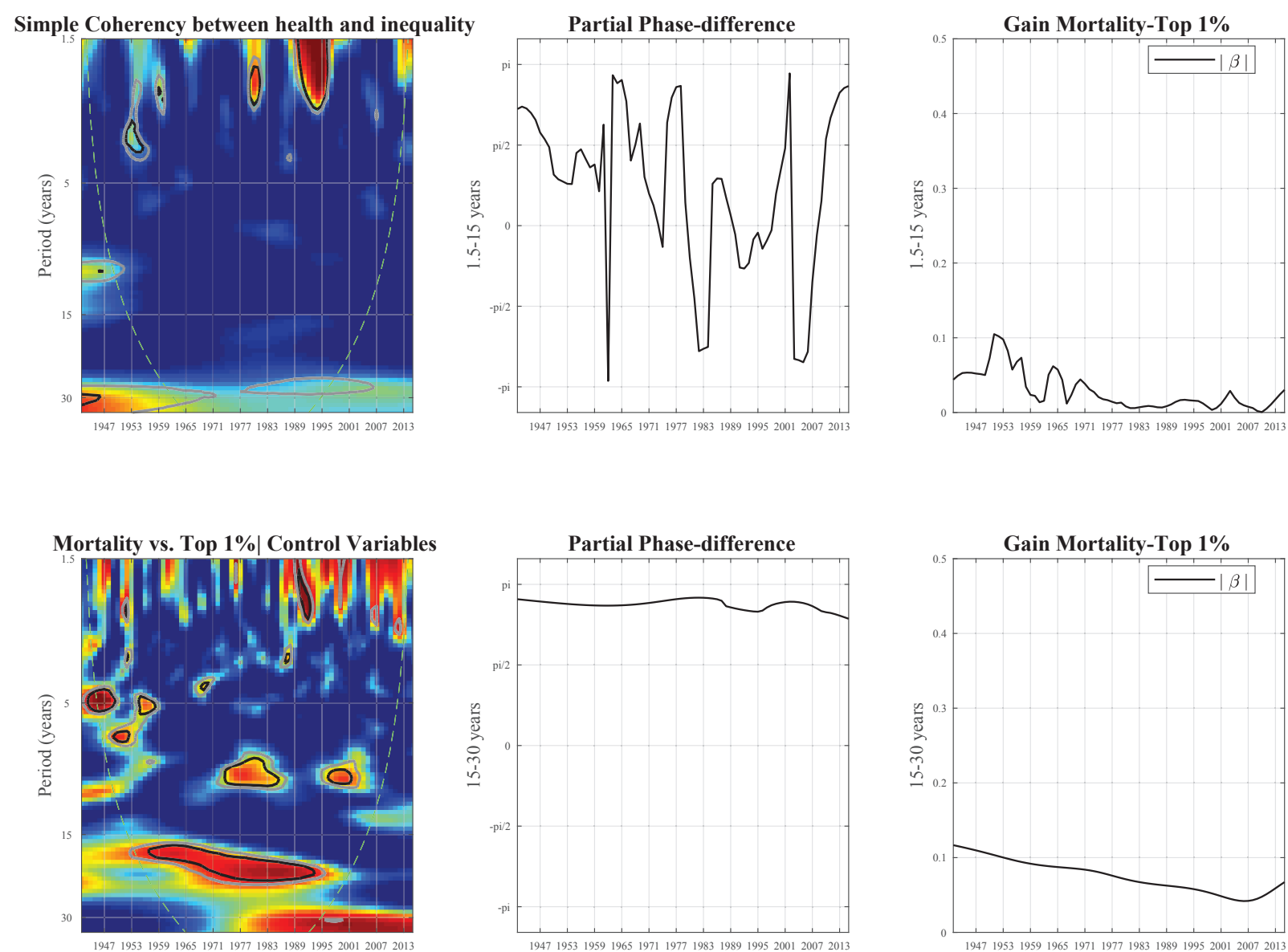

Figure 7: On the left we plot the simple wavelet coherency (top) and partial wavelet coherency between life expectancy at birth and income inequality. The black (gray) contour designates the 5\% (10\%) significance level estimated by Monte Carlo simulations (5,000 draws). The color for coherency ranges from blue (low coherency) to red (high coherency). The cone of influence, which shows the region affected by so-called edge effects, is the outside region of the thick-dashed, green line. In the center we present the partial phase-differences at different frequency bands. The limits of the confidence intervals for the mean phases are indicated in the pictures with red dashed-lines. On the right we plot the partial wavelet gain at different frequency bands. 


\section{Imprint}

\section{Bremen Papers on Economics \& Innovation}

Published by

Universität Bremen, Department of Economics,

Institute for Economic Research and Policy

Max-von-Laue-Straße 1, 28359 Bremen, Germany

\section{Editors}

Prof. Dr. Christian Cordes

Evolutionary Economics

Phone: +49 (0)421 218 66616, e-mail: c.cordes@uni-bremen.de

Prof. Dr. Dirk Fornahl

Regional and Innovation Economics

Phone: +49 (0)421 218 66530, e-mail: dfornahl@uni-bremen.de

Prof. Dr. Jutta Günther

Economics of Innovation and Structural Change

Phone: +49 (0)421 218 66630, e-mail: jutta.guenther@uni-bremen.de

Prof. Dr. André W. Heinemann

Federal and Regional Financial Relations

Phone: +49 (0)421 218 66830, e-mail: andre.heinemann@uni-bremen.de

Prof. Dr. Torben Klarl

Macroeconomics

Phone: +49 (0)421 218 66560, e-mail: tklarl@uni-bremen.de

\section{Bremen Papers on Economics \& Innovation \#2012}

Responsible Editor: Prof. Dr. Torben Klarl

All rights reserved. Bremen, Germany, 2020

ISSN 2629-3994

The working papers published in the series constitute work in progress circulated to stimulate discussion and critical comments. Views expressed represent exclusively the authors' own opinions and do not necessarily reflect those of the editors. 